Tequio 1(1), 2017: 7-13

ISSN: 2594-0546

\title{
VIOLENCIA EN LA ESCUELA
}

\section{Mercedes Araceli Ramírez-Benítez ${ }^{1}$}

Fecha de recepción: 4 de noviembre de 2016

Fecha de aceptación: 25 de mayo de 2017

Resumen - La violencia como categoría central de este trabajo viene acompañada de otras tres: el conflicto, la desigualdad y la igualdad, las cuales es imposible abarcar en todas sus dimensiones y por separado. En este sentido, la escuela se convierte en un dique de contención que nos permite delimitar el espacio de análisis y nos brinda la posibilidad de realizar algunas articulaciones con lo sociopolítico, económico y cultural de nuestro país. Empezamos por tratar de explicar cada una de estas categorías de manera independiente, para en un segundo momento articularlas y analizar cómo se manifiestan en la cotidianidad de la escuela y cómo repercuten en los sujetos que ahí desarrollan diversas prácticas. Asimismo, planteamos algunas estrategias institucionales para combatir la problemática de la violencia en la escuela.

Palabras clave:

Violencia, conflicto, desigualdad, igualdad.
Abstract - Violence as central category of this work is accompanied by three others: conflict, inequality and equality. Categories that is impossible to include in all its dimensions, and separately, in this sense the school becomes a dam that allows us to define the space of analysis and provides us with the possibility of some joint with the socio-political, economic and cultural in our country. We started by trying to explain each of these categories separately, so a second time we can articulate them and analyze how manifested in the everyday life of the school and how affect subjects that develop different practices in this institution. Likewise pose some institutional strategies that are taken to attack the problem of school violence.

\section{Keywords:}

Violence, conflict, inequality, equality. 


\section{Constructos teóricos}

onflicto, violencia y desigualdad constituyen parte de la realidad que se vive cotidianamente dentro y fuera de la escuela. Por otro lado, pareciera que existe una categoría con un sentido y significado diferente a las otras y ésta es la igualdad, que aquí la recuperaremos como un deber ser.

El conflicto, según la Unidad de apoyo a la transversalidad (2006) de Chile, es una situación en la que dos o más personas se encuentran en oposición o desacuerdo de intereses y/o posiciones incompatibles, donde las emociones y sentimientos juegan un rol importante. Para Neira (2010), es aquel desacuerdo entre personas, instituciones, grupos sociales, países, etcétera, que se genera cuando sus posiciones, intereses, necesidades, deseos o valores son contrarios entre sí, a partir del cual la relación entre las partes en contienda puede salir fortalecida o deteriorada, en función de cómo sea el proceso de resolución del problema. El conflicto, entonces, está caracterizado por varios elementos: un enfrentamiento, un desacuerdo, distintas formas de ver el mundo y de actuar en él; implica desequilibrio, incompatibilidad, pugna entre las partes, interacciones antagónicas y probablemente ninguno de los involucrados está dispuesto a ceder, se juegan intereses, pero sobre todo poder, que la mayoría de las veces no se quiere perder.

El conflicto está presente de manera inevitable ahí en donde coexisten los seres humanos; en donde hay interacción entre grupos siempre habrá desavenencias y discrepancias sobre cómo enfrentar diversas situaciones, ya sean personales o grupales. Lo importante en este caso estriba en cómo los sujetos encaran el conflicto, es decir, cómo se posicionan frente a él, para lo cual sólo hay dos opciones: el de la violencia o el de la paz. En el primero siempre imperará la intolerancia, el deseo de dañar de alguna forma a la persona o grupo con el cual se tienen diferencias; el segundo camino, que es al que apostamos, implica disposición para conocer las razones por las que existe un conflicto, a aquel o aquellos que no están de acuerdo con nuestra posición y saber su punto de vista, es decir, mostrar toda la apertura para escuchar las razones del otro, poder negociar, reconocer cuándo se tiene que ceder, cuándo no y en qué. Esto es, establecer una situación dialógica en donde ambas partes salgan lo menos dañadas posible y lo más fortalecidas que se pueda. Desde esta perspectiva, el conflicto se vislumbra como posibilidad de crecimiento y consolidación de los seres humanos, como la oportunidad de reconstruirse y reconstruir el tejido social junto con los otros.

Como señaló Federico Mayor, director general de la Unesco, en la Primera Reunión de Consulta sobre el Programa de una Cultura de Paz 1994: "la apertura y el diálogo son los medios; la paz, la democracia y la seguridad, los objetivos para lograr un futuro que refleje lo mejor de las diversas culturas, las distintas regiones y la condición humana que compartimos".

El camino de la violencia siempre dañará de una u otra manera, resquebrajará relaciones que difícilmente se podrán restaurar. La violencia como un fenómeno social indisoluble de los nexos de poder, que es en sí complejo de explicar y de entender, que puede ser analizado desde diversas aristas y que, a su vez, asume diferentes expresiones. Tan es así, que cuando se habla de violencia muchas veces se piensa en ella como el ejercicio del poder a través de la fuerza física; sin embargo, se puede expresar de variadas formas y en distintos niveles, además de que la violencia como ejercicio del poder se produce y se reproduce generando situaciones de desigualdad. Serrano e Iborra (2005, p. 10) afirman: "la violencia es toda acción u omisión intencional que, dirigida a una persona, tiende a causarle daño físico, psicológico, sexual o económico $y$, dirigida a seres humanos o animales, tiende a dañar su integridad".

Como podemos observar, la violencia referida a la acción del sujeto o sujetos sobre otro u otros tiene una finalidad: causar daño, y podríamos agregar que por medio de ella se puede provocar hasta la muerte, cuando el conflicto que la ocasiona no se resuelve por la vía pacífica. 


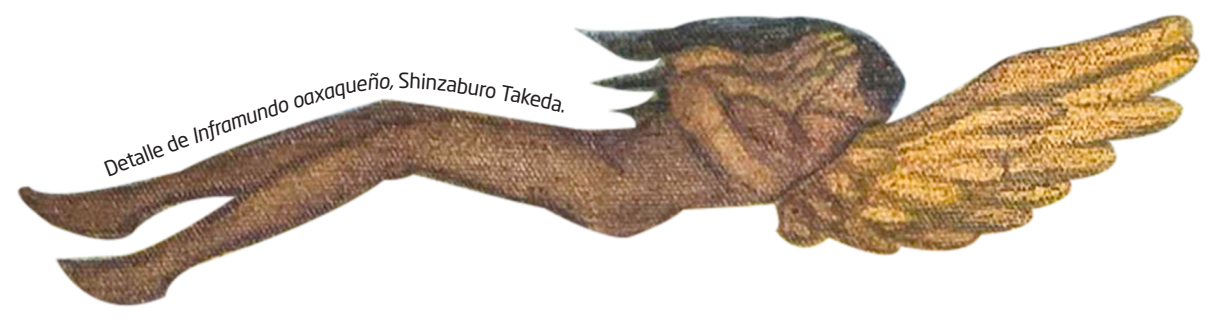

Para Sanmartín (2006), uno de los criterios para catalogar la violencia es de acuerdo con el escenario en el que ocurre, es decir, al contexto donde se genera. Por lo tanto, podría hablarse de violencia familiar, laboral, escolar, entre grupos sociales, entre países y otros. Hoy en día es posible ver que esos escenarios se multiplican y que a diario se fortalecen cada vez más; lo más lamentable es que la lucha por el poder no está mediada por la negociación, por el diálogo, no hay disposición a escuchar al otro 0 a los otros para entender que el poder se puede compartir y no sólo centralizar.

Valdez y Sanín (1996, p. 14) señalan que "La violencia es un proceso, relación o condición, por el cual un individuo o grupo viola la integridad física, social, y/o psicológica de otra persona o grupo, generando una forma de interacción en la que este proceso se reproduce". En este caso, la autora enfoca la importancia en la reproducción de la violencia, esto es, si un sujeto se desarrolla en un ambiente violento, él la puede reproducir. Por ejemplo, en México, donde existe una lucha por el poder político, por el control del mercado de estupefacientes a gran y pequeña escalas, por el control de la pornografía, de la prostitución, de la trata de blancas, de los medios masivos de comunicación, del mercado negro y otros más, la violencia es el pan de cada día.

La última noción que nos gustaría resaltar es la del Informe Mundial sobre la violencia y la salud de la Organización Mundial de la Salud (OMS, 2012, p. 3), que define a la violencia como "el uso intencional de la fuerza o el poder físico (de hecho o como amenaza) contra uno mismo, otra persona o un grupo o comunidad, que cause o tenga muchas probabilidades de causar lesiones, muerte, daño psicológico, trastornos del desarrollo o privaciones de toda índole". Su importancia radica en que hasta el momento es la definición que nos plantea la violencia ejercida hacia uno mismo, es decir, que nosotros podemos dañarnos a nosotros mismos. En nuestros días, el daño autoinfligido se convierte en una moda entre la juventud, no es que sea producto de nuestros tiempos, ya que las autoflagelaciones han sido practicadas desde tiempos inmemorables; sin embargo, hoy se ha vuelto recurrente, encontramos sujetos (jóvenes principalmente) que lastiman su cuerpo de incontables maneras y entre más violentas, mejor; resultan más atractivas aquellas que más les ocasionen dolor y que les posibiliten una escapatoria de su realidad.

A partir de lo anterior podemos decir que resolver los conflictos por la vía de la violencia fractura la comunicación, desquebraja el tejido social, pinta un paisaje desolador para los sujetos sobre quienes se ejerce esa violencia. En contraparte, tratar de solucionar los problemas mediante la paz abre nuevas esperanzas, fortalece relaciones, propicia más posibilidades de que podamos convivir en un mundo tan diverso como el nuestro.

\section{La violencia en la escuela}

En el apartado anterior dejamos en claro las relaciones que se establecen entre las categorías conflicto, violencia, igualdad y desigualdad; lo que corresponde en este momento es abordar, de manera general, qué es la violencia en la escuela.

En México, como en muchos países, la violencia se ha incrementado en las últimas décadas de manera desorbitante, lo que también ha trastocado a las escuelas en todos sus niveles $y$ ha obligado a incrementar medidas para disminuirla o erradicarla, medidas en las que participan no sólo las autoridades sino todos los sectores inmiscuidos en estas instituciones.

La violencia se ha constituido como fenómeno que afecta y lacera las relaciones sociales y la dignidad humana dentro y fuera de las escuelas, es una acción que 


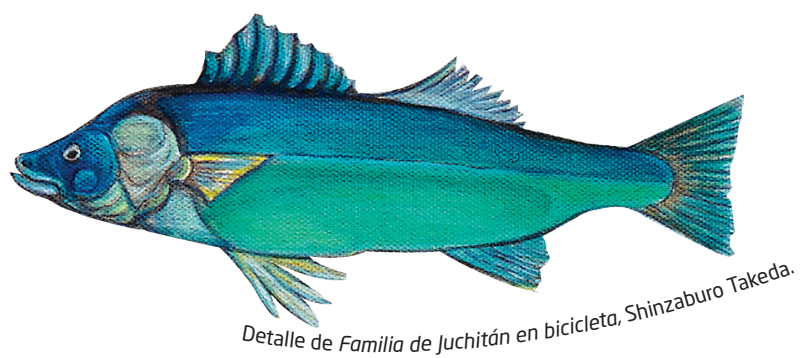

lastima a los individuos física y psicológicamente, que puede llevar quienes la ejercen a cometer los más abominables actos y a las víctimas a sufrir daños irreparables. Una de sus características es su versatilidad, ya que se puede manifestar de múltiples maneras visibles e invisibles. La violencia dentro de las instituciones educativas se ejerce en dos variantes:

Violencia oculta, caracterizada por su invisibilidad porque dominados y dominadores no la reconocen como tal. Por lo regular se configura dentro de las prácticas escolares de forma subterránea, no es percibida por los involucrados, se ejerce inconscientemente $y$ es aceptada como natural en las relaciones establecidas dentro de las escuelas.

La violencia simbólica es esa coerción que se instituye por mediación de una adhesión que el dominado no puede evitar otorgar al dominante $(y$, por lo tanto, a la dominación) cuando sólo dispone para pensarlo y pensarse 0 , mejor aún, para pensar su relación con él, de instrumentos de conocimiento que comparte con él y que, al no ser más que la forma estructurada de la relación de dominación, hacen que ésta se presente como natural (Bourdieu, 1999, pp. 224-225).

Se trata de un tipo de violencia que reproduce relaciones de poder encubiertas, en las que entran en juego roles sociales, estatus, género, posición social, en suma, todas los vínculos sociales de poder. Según la psicopedagoga clínica Laura Gutman (2011), la violencia simbólica puede ser mucho más letal de lo que en principio podemos imaginar, ya que sus diversas formas presentan la dificultad de ser identificadas como tal, puesto que no se notan; así pueden mantenerse mucho más tiempo en acción sin ser descubiertas. Por ejemplo, la clasificación que aún hacen los docentes en el aula de alumnos "sobresalientes o aplicados", alumnos "intermedios" y alumnos "burros o atrasados" sigue la "lógica" de poner en evidencia la distribución desigual del conocimiento, pero de lo que no se dan cuenta es de la marca psicológica que están dejando en los estudiantes. Así también hacen constar entre los alumnos quiénes son más importantes para el docente, en el sentido de que si van a salir al recreo o del plantel al concluir la jornada escolar, los primeros en hacerlo son los de la fila de los sobresalientes y a lo último la de los "burros o atrasados"; a los primeros se les da la palabra cuando quieren participar, después a los demás, salvo que se desee destacar que los "otros no saben lo que se les está preguntando" y se ponga como modelo a seguir a los "destacados".

También podríamos ejemplificar esta violencia simbólica con algunas frases de los profesores:

"A ver, Juanita, ¿ya acabaste el ejercicio?". El mismo maestros responde: "no, ¿verdad?, y entonces, mi vida, ¿cómo quieres que te cambie de fila? Para que la próxima vez te apures y obedezcas cuando se te dice que te apures, no vas a salir a recreo y de tarea me vas a hacer tres planas de: debo apurarme en clase y no estar platicando ni jugando cuando debo de estar trabajando. ¿Entendiste, corazón? Y ahora apúrate si no quieres que te deje sin recreo toda la semana".

"Pero, Juanito, ¿qué tienes en la cabeza? ¿Qué no piensas? Corazón, por favor, concéntrate en lo que se te pregunta antes de contestar, ¿sí?".

A partir de las situaciones áulicas recuperadas, pareciera que para los docentes en cuestión es "natural" clasificar a los alumnos, humillarlos, castigarlos o ignorarlos, con la finalidad de que sean "obedientes", para sepan quién es el que manda en el salón; lo peor del caso es que muchas veces lo hacen de manera inconsciente, es decir, replican la misma 
educación que recibieron ellos. Por otro lado, la mayoría de las veces los alumnos lo aceptan, puesto que en casa les recalcaron que a la escuela se va a aprender y a obedecer, lo que nos da elementos necesarios para manifestar que tanto maestros como alumnos han interiorizado roles sociales determinados. Aun así, cabe señalar que no todos los docentes ni todos los alumnos actúan de esta forma, hay quienes desde el lugar que ocupan ejercen resistencia.

Veamos el siguiente testimonio:

María le dice a la maestra: "Paco me está molestando, me hace gestos y me dice chillona". La maestra le contesta: "Mari, ya deja de quejarte, algo le has de haber hecho a tu compañero para que te moleste, tú tienes la culpa; anda, vete a tu lugar y apúrate". "Pero, maestra, siempre me está haciendo señas y muchos gestos malos y me quita mis cosas, yo no le estoy haciendo nada, pero le voy a decir a mi papá".

Podemos apreciar, además de lo ya mencionado, la repetición de las relaciones de género, en cuanto que se le dice a la niña que ella tiene la culpa de ser molestada, no se indaga o se pregunta cómo se suscitó dicho conflicto entre los alumnos, sino que de entrada se le da la razón al niño. La pregunta para la docente sería: ¿las mujeres tienen la culpa de la violencia que ejercen los hombres contra ellas? Lo más lamentable es que ella como mujer propicie este tipo de situaciones. La violencia simbólica no se ejerce únicamente de docentes hacia los alumnos, sino también entre pares, como lo evidencia el último testimonio; también los profesores la padecen en el trato con sus compañeros o jefes.

Violencia abierta: es descarada, visible, ejercida a través de la fuerza de quien detenta mayor poder en las relaciones sociales. La podemos encontrar en espacios dentro del plantel, como por ejemplo:

- En el salón de clases: el aula no es solamente el sitio en donde se generan aprendizajes, donde se manifiesta la violencia simbólica o donde se comparten miles de vivencias entre los alumnos, también es ahí donde se ponen de manifiesto verdaderas luchas de poder, las cuales se tratan de ganar mediante el uso de la fuerza, lastimando a los más débiles, a través de golpes, rasguños y patadas, para medir quién tiene más fuerza o aguanta más, 0 en su defecto, aquellas agresiones disfrazadas de juegos. También están los casos de maestros que pueden dar una "palmadita" a los alumnos sin que sea un golpe, según ellos.

- El patio de la escuela: este espacio se convierte en un verdadero campo de batalla, en el que se puede aprovechar cualquier descuido para dañar al compañero con el que se tenga alguna rencilla, o disfrazar la agresión de juego, como por ejemplo "el burro seguido", en la que hay varios alumnos que se ponen con las piernas abiertas, agachados hasta que las manos tocan el piso y separados por aproximadamente medio metro, una fila de niños los saltan dándoles una patada en el trasero lo más fuerte que puedan; cualquier juego se puede aprovechar para agredir al compañero.

- La zona perimetral: este lugar siempre ha sido el preferido por los alumnos, tanto del sexo masculino como del femenino, para solucionar conflictos a través de los golpes. Cuando no pueden pelearse dentro de la escuela, la frase más común es: "nos vemos a la salida, a ver cómo nos va". Los daños físicos han llegado a ser irreparables, ya que lamentablemente se ha provocado la muerte de las víctimas.

La violencia, ya sea oculta o abierta, daña física y psicológicamente a los sujetos que la padecen, dejando en ellos una sensación de impotencia, estrés, desmotivación para seguir en la escuela, efectos negativos en el rendimiento escolar, baja autoestima, traumas que les impiden tener buenas relaciones con sus compañeros e incluso algunos han llegado al suicidio. Asimismo, podemos señalar que la violencia lastima no sólo a los agredidos sino también a los agresores. 


\section{Posibles causas de violencia en la escuela}

Hay muchos motivos por los cuales se manifiesta la violencia dentro de la escuela, entre los que podemos señalar:

- Familiares: el alumno puede mostrar actitudes agresivas dentro y fuera de la escuela como expresión de lo que vive en un entorno familiar poco afectivo, en donde no está presente algún padre o están en situación de desempleo, abandono de la responsabilidad de ser padres por el exceso de trabajo, divorcio, violencia, abuso o humillación ejercida por los progenitores, hermanos mayores o familiares que habitan bajo el mismo techo. El alumno imita a los adultos, o tal vez sea violento porque vive bajo constante presión para tener éxito en sus actividades o, por el contrario, quizá esté sumamente mimado, entre otras variables.

- Escolares: en muchos estudiantes prevalece el mito de que para ser populares deben de hacerse "respetar" por cualquier medio y entre más violento, mejor; estos alumnos tienen una escasa o nula conciencia de lo que significa la dignidad humana y lo único que les preocupa es tener el reconocimiento de sus adeptos.

- Medios de comunicación masivos: Desde décadas atrás se han convertido en las "nanas" o zona de refugio de niños y adolescentes, sin que muchas veces haya un control de lo que ven, hacen o con quién se comunican. Los menores buscan copiar modelos o estereotipos de los personajes que más admiran, sin importar que éstos sean violentos 0 no. Así también, a través de estos medios muchos alumnos se ponen al tanto de la realidad de nuestro país, de tal manera que se enteran de la violencia que se vive entre políticos, narcotraficantes, delincuentes, secuestradores etcétera; es decir, de la cotidianidad.

Pensamos que la violencia surge en la escuela cuando varios de los elementos señalados se conjugan en un mismo sujeto, entonces hay más probabilidades de que esta persona quiera sobresalir dentro y fuera del colegio por medio de actos violentos.

\section{Consideraciones finales}

Algunas de las repercusiones que trae consigo la violencia son: en la víctima, el miedo y rechazo al lugar en donde sufre la agresión, así como pérdida de confianza en sí misma y en los demás, ya sea porque la están agrediendo o por que otros vean cómo la agreden y no hagan nada, baja autoestima y bajo rendimiento escolar. Por su parte, el agresor cada vez quiere controlar a más compañeros o demostrarles lo "superior" que es, al grado de que hasta los que alguna vez lo apoyaron y lo tomaron como modelo, lo van dejando paulatinamente solo; él no siente ninguna empatía, empieza a tener problemas de aprovechamiento escolar. Finalmente, en las personas que no participan directamente de la violencia, pero que conviven con ella sin procurar evitarla puede producir, aunque en menor grado, algunas de estas consecuencias: miedo a convertirse en víctima, reducción de la empatía y contribuyen a que aumente la falta de sensibilidad, apatía y la falta de solidaridad respecto de los problemas de los demás.

Es por lo anterior que la violencia en los centros educativos se ha constituido en un problema que inmiscuye a muchos sectores de la sociedad, a partir de lo cual se han implementado políticas para el desarrollo de una educación para la paz y se llevan a cabo estrategias orientadas a exterminarla, lo cual representa un verdadero reto para padres de familia y educadores, ya que hasta que no cambié la situación económica, política y social, los resultados no van a ser del todo favorables.

\section{Referencias}

Bourdieu, P. (1999). Meditaciones pascalianas. México: Anagrama.

Gutman, L. (2011). Crianza: violencias invisibles y adicciones. Barcelona: RBA libros.

Hernández, M. Á. (2002). Reflexiones sobre la educación siglo XXI. La agresividad en la escuela. Ponencia presentada en el Congreso internacional 
virtual de educación 2001, Universidad de las Islas Baleares, España.

Montiel, K. (2011). Autoflagelación desde una mirada freudiana, pulsión de muerte e identificación. Recuperado de: https://2010dementes.wordpress. com/.../autoflagelacion-desde

Neira, R. (2010). ¿Qué es el conflicto? Recuperado de: https://www.mailxmail.com/curso-conflictoresolución-problemas/

Organización Mundial de la Salud (OMS). (2012). Informe Mundial sobre la violencia y la salud (sinopsis). Ginebra: autor.

Sanmartín, J. (2006). ¿Qué es esa cosa llamada violencia? Diario de Campo, suplemento, Instituto Nacional de Antropología e Historia, 9-29.
Serrano, Á. e Iborra, I. (2005). Informe violencia entre compañeros de escuela. Serie Documentos, núm. 9. España: Centro Reina Sofía para el Estudio de la Violencia.

UNESCO. (1994). Informe final: Primera reunión de consulta sobre el Programa Cultura de Paz. París, 27-29 sep.

Unidad de Apoyo a la Transversalidad. (2006). Conceptos clave para la resolución pacífica de conflictos en el ámbito escolar. Cartilla de trabajo aprender a convivir (Inscripción No. 157). Santiago de Chile: Ministerio de Educación.

Valdez, R. \& Sanín, L. H. (1996). La violencia doméstica durante el embarazo y su relación con el peso al nacer. Salud Pública de México, 38(5), 352-362.

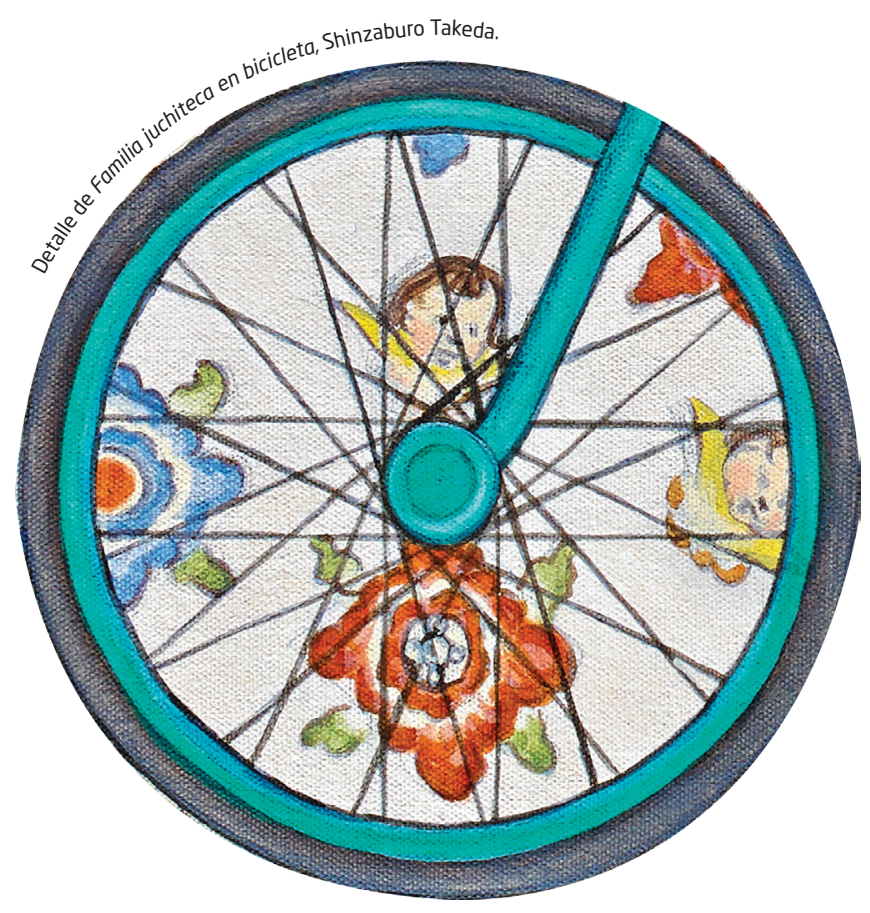

